\title{
Promoting sustainable development and universities cooperation
}

\author{
Elena Makarova ${ }^{1 *}$ and Jing Wang ${ }^{2}$ \\ ${ }^{1}$ Ural State University of Economics, 620144, 8 Marta Str., 62, Ekaterinburg, Russia \\ ${ }^{2}$ Shandong University, 27 Shandu Nanlu Jinan, 250100 Shandong, People's Republic of China
}

\begin{abstract}
The article presents experiences in developing key sustainability competences in the context of universities' collaboration projects. Examples of education for sustainable development principles' implications in the process of teaching foreign languages are described. The analyses of cooperation of a Russian university with a regional university and an international university are given. The emphasis is made on possibilities of using modern digital technologies and online technologies for students' communication at distance. Students' perception of participating in cooperation projects is outlined. Ways of teaching staff collaboration are discussed and analysed. The results demonstrate the possibility of establishing mutually beneficial academic relationships allowing effective implementing principles of sustainable development in practice.
\end{abstract}

\section{Introduction}

Changes in existing education structures and organizations have been announced among the key factors for achieving sustainable development goals. Living in a sustainable world demands understanding of the challenges the international community is facing today. Such understanding can hardly be reached without defining common values and sharing ideas and knowledge necessary for taking actions leading to sustainability in all spheres of modern life. The role of quality education in this process cannot be overestimated. At different levels of educational system children and young adults obtain knowledge and acquire essential skills which are required for sustainable development. Among these skills ability to make decisions, take responsibility, work in a global team, and communicate effectively to reach mutual understanding are named to be crucial. Joint efforts which have to be made to achieve sustainable development in the local and global contexts demand that despite being educated young people must be tolerant, be able to accept diversity and respect different cultures.

All types of educational institutions aim at introducing and implementing elements of education for sustainable development into the process of learning. The role of schools in raising new generations caring for the future of natural and social environments is extremely important [1]. Approaches to efficient school teaching for sustainability are

\footnotetext{
*Corresponding author: makarovayn@mail.ru
} 
debated in modern literature [2, 3, 4]. Speaking about higher education the concept of a sustainable university has been under discussion for the last decades [5]. Ways of implementing education for sustainable development policies are often viewed in connection with using innovative strategies, as well as applying new approaches to university education [6]. Developing sustainability competences in higher education prove to be effectively achieved through introducing into the university environment elements of active, project-based, research-based and self-organized learning [7]. Practices of implementing sustainable development principles in university education in the context of regional and international cooperation haven't been given much attention in spite of having the potential to be efficient.

International cooperation development policy is aimed at supporting cultural diversity. International cooperation for sustainable development and implementing its ideas cover a wide range of areas [8]. Collaboration in education is vital as living in a global society demands new attitudes to nature and society. These attitudes as well as the essential skills can be better acquired in the cooperative and diverse environment. Cooperation in higher education is aimed at assisting in forming world's strong educational system and as a result, in building a sustainable world. Over the past decade universities have demonstrated readiness and potential for the process of internalization and have shown good examples of applying joint efforts in establishing relationships aimed at promoting principles of sustainability and forming students' global-related attitudes. Approaches to universities international cooperation and strategies for its establishment attract attention of educators and researches $[9,10]$. Results of effective partnerships for sustainable development with the Russian educational establishments' participation, namely creation of a Komi-Finnish network of environmental and cultural education, are presented in the studies by L. V. Chalysheva [11] and V. Companets [12]. Collaboration in the field of education involves a wide range of areas: improving education to satisfy the needs of labour market, developing efficient communication technologies, providing teacher training and development programs [13].

Fostering collaboration between universities is especially important in the time of COVID-19 pandemic. In order to facilitate learning opportunities UNESCO's COVID-19 Global Education Coalition aims to seek equitable solutions and universal access, help countries to mobilize resources and implement innovative solutions [14].

Today there are evident uncertainties for active university students' mobility and internalization. Opportunities of studying abroad are limited. There are also concerns about growth of racial discrimination connected with fears that international students can be regarded as "unsafe" and be treated unproperly [15]. There are also opinions that international education tends to be unattractive without daily campus communication [16].

However, many higher educational institutions have successfully implemented online learning and have demonstrated readiness for education system digital transformation [17, 18]. Cooperation and exchange activities can be restored on the grounds of extensive use of information technologies and new online solutions, including virtual mobility and virtual collaboration.

\section{Materials and methods}

The article presents experiences of partnerships between the Department of Business Foreign languages (Ural State University of Economics), the Department of Foreign Languages for Humanities (Petrozavodsk State University), and the Depqrtment of the Russian Language and Culture (The University of Ciego de Ávila "Máximo Gómez Báez", Cuba). The departments of languages work in collaboration to develop both students' professional competences and their "soft skills". The processes of carrying out joint 
projects aimed at implementing principles of education for sustainable development and their results are analysed and described. On the basis of the survey data, students' progress in acquiring key competences for sustainable development as well as their perception of the projects' relevance to the field of study and their future career are revealed.

\section{Results and discussion}

\subsection{Regional cooperation}

Department of Foreign Languages for Humanities (Petrozavodsk State University) has been working on developing and introducing experimental teaching methods of non-linguists through modelling a unified foreign language surroundings outside the natural language environment for more than a decade. 2019-2020 academic year saw the beginning of collaboration between the Department of Foreign Languages for Humanities and the Department of Business Foreign languages.

During the academic year of 2019-2020 5 joint projects with the participation of firstand second-year students majoring in information technologies and management were successfully implemented at USUE. All the events were initiated by the Department of Foreign Languages for Humanities (Petrozavodsk State University). The list of them as well as a short description of the outcomes are given below.

1. Creating digital stories on the topic "My University. My specialty/field of study". Apart from improving students' language skills the implementation of this project contributed to their adaptation to the university environment. The results of the previous research prove that introducing "digital storytelling" into the educational process has had a positive impact on students' willingness to participate in classroom activities as well as on their professional competences and soft skills' formation [19].

2. International contest of professionally-oriented films in the English language. Students majoring in management produced two films on the future possibilities in building their professional career and typical mistakes of modern managers. In the process of making the films the learners successfully tried on the roles of a script-writer, an actor/actress, a film director, a cameraman a producer and a manager. According to the survey conducted to reveal the students' perception of the project and its relevance to their field of study, $90 \%$ of the participants found the film-making process highly relevant to area of their professional interests. Choosing among the benefits from the project's participation, all the students considered teamwork to be the most important. In their commentaries the majority agreed that everybody managed to act as an efficient team member, even though before starting the project about half of the learners were sceptical about the result.

3. Creation of multimedia content on one of the crucial social topics, such as "Say NO! to drugs", "A world without violence", "Don't ask what the country can do for you, ask what you can do for the country". The relevance of the project to sustainable development principles allowed concentrating students' attention on such sustainable development values as freedom, shared responsibility, solidarity, equality and the others. Most students touched upon variety of social issues and policies in both local and global context and offered the ways of their prevention and solutions.

4. The first all-Russian Olympiad in machine translation post-editing. Though postediting machine-translated training is not provided in the course of studies, advances and extensive use of machine translation technology call for students' acquiring and developing skills in this field. Participation in this project proved students' understanding of the 
machine translation post-editing skills' significance and relevance to various areas of studies.

5. The first all-Russian Olympiad aimed at developing students' listening comprehension skills. The materials presented to the students included lectures by famous British scientists. Apart from improving their listening comprehension skills the learners had a chance to listen to the best representatives of oldest British universities and get involved into international educational environment, as well as realize the importance of looking at social issues from other people's perspective.

In 2019 the Department of Business Foreign languages initiated and organized international scientific contest "Socio-cultural links as the basis for trust economy". Students' representative of Petrozavodsk State University participated in the contest demonstrating excellent presentation and competitive skills.

Professional discussions and debate about successful students' projects implementation have led to the two departments' joint research activities. Scientific collaboration allows sharing teaching experiences and developing teaching innovation methodologies. The results of collaborative efforts aimed at seeking new approaches to foreign language education in the context of Russian higher educational system and raising a new generation of young adults prepared to live sustainably, are presented in a number of joint publications by the Department of Foreign Languages for Humanities' and the Department of Business Foreign languages' staff $[20,21]$. One of the most significant partnership's outcomes is the readiness of the two departments to use modern digital and communication technologies in both the process of teaching and professional communication. In spite of the of COVID-19 pandemic challenges, the teaching staff and the students aim to continue joint activities and projects, using the opportunities for developing effective $t$ communication at distance.

\subsection{International cooperation}

Promoting principles of education for sustainable development suggests universities' integration into the international educational environment and international university cooperation. Collaboration between the Department of Business Foreign languages and the department of the Russian Language and Culture (The University of Ciego de Ávila “Máximo Gómez Báez", Cuba) started back in 2014. Since 2014 numerous students' and teaching staff's projects have been implemented within this partnership. A good example of effective cooperation concerns the activities within the project "Influence of Russian culture on the socio-economic development of Ciego de Ávila province". The Russian University students and the teaching staff have had unique opportunities to participate in the international scientific conference "Invitation to the Russian world: Scientific readings" and exchange publications on topics related to the teaching foreign languages, including the Russian language. The collaboration within this project has allowed its participants to expand their knowledge of Russian-Cuban relations and contribute to the events related to the study of the Russian language at the Cuban University.

Since 2014 students of the University of Ciego de Ávila "Máximo Gómez Báez" have taken part in the Eurasian Youth Forums held at Ural State University of Economics annually. Modern communication technologies allowed Cuban students' virtual presence at various forum activities. Distance has never prevented their engagement and active participation in the following events:

1. Contest of social advertising posters.

2. Students' conference "World without war: youth discovering World War II history: world without war is a better world.

3. Students' round table "East and West: Dialogue of Cultures. Myth or Reality".

4. Students' conference "Green Economy". 
5. Students' conference "Russia in the global world: challenges of the 21 st century".

6. International scientific contest "Socio-cultural links as the basis for trust economy".

Cuban students' projects and their results are regularly presented in conferences' articles collections. The activities described above, develop students' soft skills such as sociability, emotional intelligence, creativity and self-motivation. They are also aimed at forming students' foreign language communicative competence, and teach effective interaction with a foreign partner.

International cooperation between the teaching stuff finds its reflection in joint research activities, scientific research articles publishing, video conferencing, and other projects, contributing to professional development. Experiences in establishing beneficial partnership at distance and creating mutual educational environment allow continuing effective collaboration in the new reality of pandemic and plan joint activities aimed at developing students' better understanding of sustainable world.

\section{Conclusion}

Observations of experiences in establishing cooperation between universities in regional and international context, analyses of joint students and university teaching staff activities allow concluding of their beneficial outcomes for the process of promoting and implementing principles of sustainable development. Building educational partnerships is directed at providing students with opportunities to participate in joint projects and learn more about other regions and cultures. It also promotes creating productive and effective learning environment, introducing innovative teaching methods and improving communication skills at distance. The study proves the joints projects' motivational effect. Events organized within collaborative partnerships have proved their effectiveness in learners" development of the key sustainable development competences, such as planning, self-motivation, cross-cultural understanding, realizing innovative projects, competence for cooperation in groups, participation, communication, and the others. The experiences encourage further development of effective collaboration and serve as a ground for establishing effective mechanisms of academic communication at distance.

\section{References}

1. E. O. Anyolo, S. Kärkkäinen, T. Keinonen, JTEFS, 20 (2018)

2. E. Sinakou, V. Donche, J. Boeve-de Pauw, P. Van Petegem, Sustainability, 11 (2019)

3. A. Mohanty, D. Dash, J. Sustain. Dev, 7 (2018)

4. T. Ichinose, JTEFS, 19 (2017)

5. W. W. Choong, E. Syarafina, Int. J. Recent Tech. Eng, 8 (2019)

6. M. Vergara, B. E. Sandia Saldivia, RISTI - Revista Iberica de Sistemas e Tecnologias de Informacao, 1 (2019)

7. M. Riecmann, Education for Sustainability in Higher Education - achievements and prospects (2015)

8. G. Safonov, N. Piskulova, New Challenges in Sustainable Development for Russia and the World (2018)

9. W. Chan, J. Stud. Int. Educ, 8 (2004)

10. Q. Zha, H. Wu, R. Hayhoe, High Educ (Dordr), 78 (2019)

11. L. V. Chalysheva, Lifelong learning: Continuous education for sustainable development (2014) 
12. V. Kompanets, J. Väätänen, K. Novikova, ICERI 2014 Proceedings (2014)

13. https://internationalednews.com/2014/04/01/international-cooperation-in-education/

14. https://www.un.org/sustainabledevelopment/education/

15. M. Waruru, University World News, 16 July (2020).

16. L. H. Phan, T. Phung, University World News, 29 August (2020).

17. B. Bensaid, T. Brahimi, RII Forum (2020)

18. A. Khandelwal, A. Kumar, Int. J. Adv. Res, 8 (2020)

19. E. N. Makarova, I. S. Pirozhkova, Digitalization of Education: History, Trends and Prospects (2020)

20. A. Ananyina, I. Abramova, E. Makarova, E. Shishmolina, New Silk Road: Business Cooperation and Prospective of Economic Development (2019)

21. I. E. Abramova, E. N. Makarova, Perspectives of Science and Education, 2 (2019) 